\title{
Correction: The Relationship Between Health Management and Information Behavior Over Time: A Study of the Illness Journeys of People Living With Fibromyalgia
}

Annie T Chen, MSIS, PhD

University of Washington School of Medicine, Department of Biomedical Informatics and Medical Education, Seattle, WA, United States

Corresponding Author:

Annie T Chen, MSIS, PhD

University of Washington School of Medicine

Department of Biomedical Informatics and Medical Education

850 Republican St., Box 358047

Seattle, WA, 98109

United States

Phone: 12062219218

Email: atchen@uw.edu

\section{Related Article:}

Correction of: https://www.jmir.org/2016/10/e269/

(J Med Internet Res 2020;22(8):e23597) doi: 10.2196/23597

In "The Relationship Between Health Management and Information Behavior Over Time: A Study of the Illness Journeys of People Living With Fibromyalgia" (JMIR 2016;18(10):e269) the author noted an error in Table 2. Some values under the section "Employment status" were listed incorrectly.

Values for "Student" were originally listed as:

$$
n=11,47.8 \%
$$

The correct values for "Student" are:

$$
n=3,13.0 \%
$$

Values for "Not employed" were originally listed as:

$$
n=3,13.0 \%
$$

The correct values for "Not employed" are:

$$
n=1,4.3 \%
$$

The correction will appear in the online version of the paper on the JMIR Publications website on August 20, 2020, together with the publication of this correction notice. Because this was made after submission to PubMed, PubMed Central, and other full-text repositories, the corrected article has also been resubmitted to those repositories.

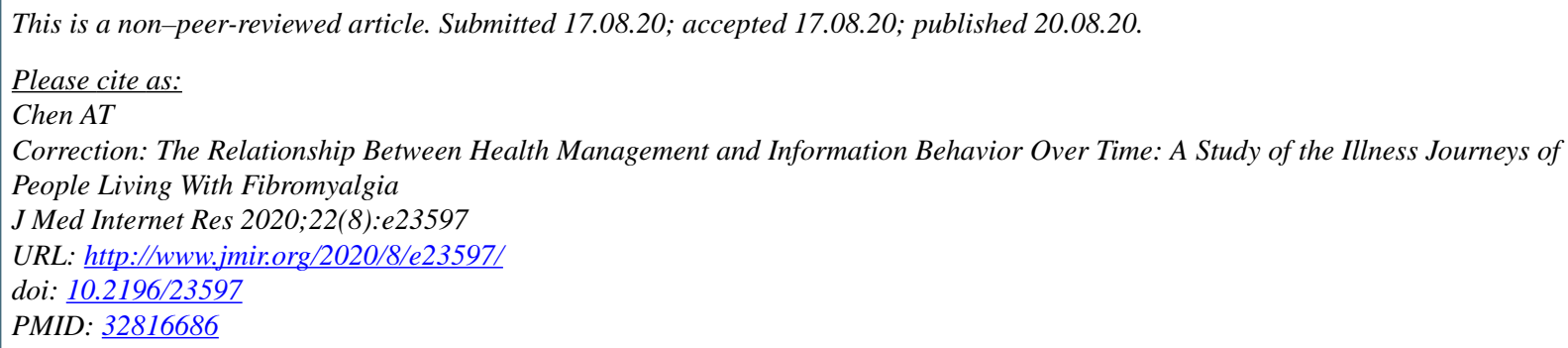

(C)Annie T Chen. Originally published in the Journal of Medical Internet Research (http://www.jmir.org), 20.08.2020. This is an open-access article distributed under the terms of the Creative Commons Attribution License (https://creativecommons.org/licenses/by/4.0/), which permits unrestricted use, distribution, and reproduction in any medium, provided the original work, first published in the Journal of Medical Internet Research, is properly cited. The complete bibliographic information, a link to the original publication on http://www.jmir.org/, as well as this copyright and license information must be included. 